\title{
GREEN-WAVELENGTH TERRESTRIAL LASER SCANNING OF MOUNTAIN CHANNEL
}

\author{
N. Miura ${ }^{\mathrm{a}, *}$, Y. Asano $^{\mathrm{a}}$ \\ ${ }^{\text {a }}$ Graduate School of Agricultural and Life Sciences, the University of Tokyo, 1-1-1 Yayoi Bunkyo-ku, Tokyo, Japan - \\ (miura, yasano)@uf.a.u-tokyo.ac.jp
}

KEY WORDS: Hydrology, TLS, DEM/DTM, Underwater, Acquisition

\begin{abstract}
:
It is crucial to understand and predict how the water and sediment flow in mountain channels for better disaster risk management. Detailed and quantitative measurement of channel and stream-bed structure is in great demand. In this paper, the utility of greenwavelength TLS for measurement of submerged stream-bed is preliminary examined in a steep mountain channel. The ability of through water measurement is evaluated in terms of water depth and flow velocity. Automated extraction of submerged objects is also tested. The results of comparison of water depth derived by TLS and survey displayed significant correlation between them, presenting good performance of green-wavelength TLS for measurement of submerged stream-bed. The analysis using a Generalized Liner Model (GLM) indicated that each of water depth and flow velocity alone does not affect the accuracy of TLS measurement, however, the interaction between water depth and flow velocity may have an influence. The attempt to automatically extract the dimension of submerged objects was partially successful, achieving maximum error of $+0.8 \mathrm{~cm}$ for two objects.
\end{abstract}

\section{INTRODUCTION}

It has been one of major concerns that recent global climate change increases the frequency and magnitude of heavy rains in Japan, which may cause frequent severe flood and sediment related disaster. Since more than $60 \%$ of national land in Japan is covered by mountains and forests, it is crucial to understand and predict how the water and sediment flow in mountain channels for better disaster risk management. Mountain channels, which consist of steep bed slope, highly variable bed material size and large grain, often develop characteristic bedforms such as step-pool morphology. This heterogeneous and complex nature of mountain channel makes it difficult for quantitative measurement, since conventional survey needs manpower and is often difficult to conduct due to access and safety issues. Therefore, the hydraulics and hydrology of mountain channels remain less understood than those of lower gradient alluvial channels (e.g. Wohl, 2010). It has been reported that the flow and flow resistance are largely controlled by gradient, fluvial morphology and stream-bed gravel size (e.g. Lee and Ferguson, 2002; Montogomery and Buffington, 1997; Wilcox et al., 2006; Wohl et al., 2007; Zimmermann and Church, 2001). Therefore, detailed and quantitative measurement of mountain channel and stream-bed structure is in great demand.

Terrestrial Laser Scanning (TLS) has demonstrated its highly accurate and rapid 3D data acquisition with mobility in the last decade. The technology has been mainly used in surveying. However, the continuous evolution of this technology enabled the ease of data capture and expanded its application outside traditional surveying disciplines (Large and Heritage, 2009). The application of TLS for grain-scale data in fluvial environments has been reported. Hodge et al.(2009) described the methodology to acquire and process TLS data to reconstruct Digital Terrain Models (DTMs) from fluvial sediment surfaces. The authors found that the point precision is less than $5 \mathrm{~mm}$, which leads even smaller precision of created DTMs, and is limited by mainly a random scanner error and the interaction of the laser footprint with surface geometry, rather than the effect of surface reflectivity. However, this method was applied only for dried gravel bed during dry periods since the sensor operates the wavelength of near infrared red which is most commonly used wavelength for commercial TLS, however, absorbed by water. Milan et al. (2010) also used TLS operated at infrared region of wavelength to define water surface roughness. Although the reflected signal produced an extremely detailed and objective map of the water surface roughness, the issues of data loss due to absorption and transmission through the water remained. For the through-water measurement, green wavelength TLS showed promising results. Smith et al. (2012) utilized a Leica ScanStation TLS which operates nd:YAG 532 $\mathrm{nm}$ pulsed laser to demonstrate through-water scanning in laboratory and field experiments. The authors developed a correction method based on Snell's Law for underwater data collected by TLS as systematic error arises from refraction at the air-water interface. When light travels from air to water, it refracts (Figure 1). The relationship between the angles of incidence $\theta_{a}$ and refraction $\theta_{w}$ of light passing through the boundary between the two media is described as

$$
\frac{\sin \theta_{\mathrm{a}}}{\sin \theta_{\mathrm{w}}}=n
$$

$$
\text { where } \begin{aligned}
\mathrm{n} & =\text { refractive index } \\
\theta_{a} & =\text { angles of incidence } \\
\theta_{w} & =\text { refraction of light }
\end{aligned}
$$

The refractive index from air to clear water is 1.33 and its variation for different temperatures is very small (Butler et al., 2002).

\footnotetext{
* Corresponding author.
} 


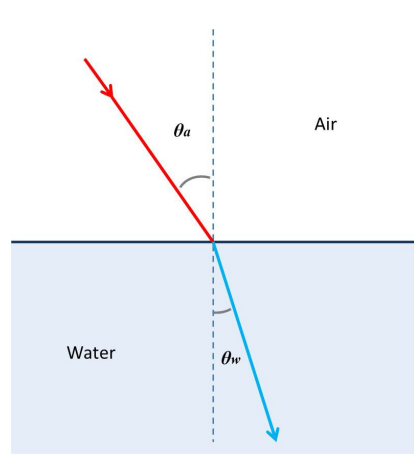

Figure 1. Refraction of light between air and water

However, TLS is not built specifically for through-water scanning and collected data takes no account of this refraction. Therefore, the authors calculated the actual position of submerged surveyed points from recorded locations of the points, the refractive index and the water surface level relative to the scanner origin, using geometry of measurement and trigonometric function. With water refraction corrected data, the authors found that the introduced mean error was less than 5 $\mathrm{mm}$ through $200 \mathrm{~mm}$ of water in laboratory validation. The potential of green-wavelength TLS for through-water measurement was shown. However, this was conducted under ideal conditions such as laboratory setting and field of relatively shallow, calm and clear water column with gravel beds. More experiments are required in a different type of natural fluvial setting to assess the applicability of this technique.

In this paper, the utility of green-wavelength TLS for measurement of submerged stream-bed is preliminary examined in a steep mountain channel with flow and complex stream-bed up to approximately $70 \mathrm{~cm}$ deep. The ability of through water measurement is evaluated in terms of water depth and flow velocity. Automated extraction of submerged objects is also tested.

\section{METHODS}

\subsection{Study area}

The mountain channel we studied locates in the Aono Research Forest, the Arboricultural Research Institute of the University of Tokyo Forests, Izu Peninsula in Japan (Figure 2). In this area, average annual precipitation and temperature from 1977 to 2006 are 2,148 $\mathrm{mm}$ and 15.3 degree Celsius, respectively. The watershed is in the mixed forest of beech tree, Japanese cedar and camphor tree, and underlined by tertiary sedimentary rock. The channel is approximately $6 \mathrm{~m}$ in flow width during low flow and its bed slope is 0.061 . The catchment area is approximately $2.67 \mathrm{~km}^{2}$. Morphology of the channel is classified as step-pool according to Montgomery and Buffington (1997). The size of grain in stream-bed, $D_{50}, D_{84}$ and $\mathrm{D}_{95}$, which are $50^{\text {th }}, 84^{\text {th }}$ and $95^{\text {th }}$ percentile of cumulative grain size distribution, are $0.16,0.45$ and $0.75 \mathrm{~m}$, respectively (Asano and Uchida, 2013).

\subsection{Terrestrial Laser Scanning}

The laser data was acquired using Leica ScanStation C10 over an approximately $50 \mathrm{~m}$ reach of the mountain channel in May 2013. The sensor is operated with $532 \mathrm{~nm}$ pulsed laser. The accuracy of single measurement is $6 \mathrm{~mm}$ for position, $4 \mathrm{~mm}$ for distance and $60 \mu \mathrm{rad}$ for angle (Leica Geosystems, 2013). Scan

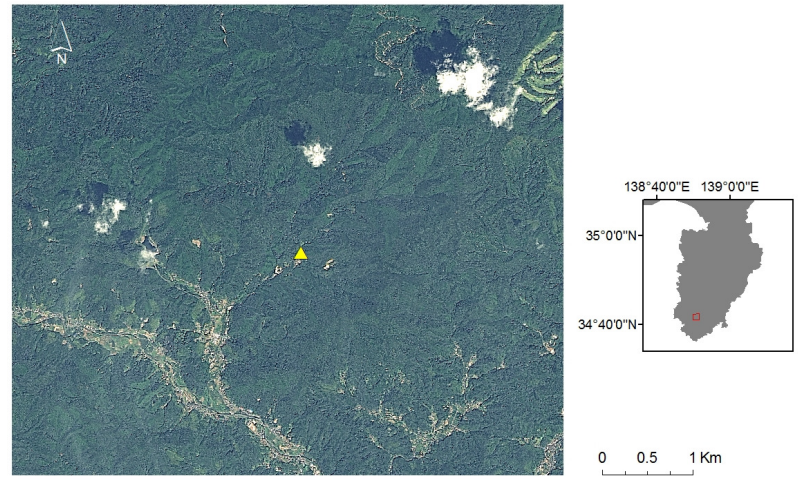

Figure 2. Study area: the Aono Research Forest, the Arboricultural Research Institute of the University of Tokyo Forests, Izu Peninsula in Japan (ALOS AVNIR2, acquired on

August 8,2009 ). A triangle shows the location of TLS measurement.

rate is maximum 50,000 points per second with minimum point spacing of $5 \mathrm{~mm}$. Multiple measurements were conducted by positioning TLS at several different locations along the channel, so that all data were collected within short ranges $(<5 \mathrm{~m})$. In order to identify the water surface in the point cloud later in the laboratory, planar objects of foamed styrol were floated in the channel. Underwater data was water refraction corrected using the method of Smith et al. (2012), which utilizes Leica ScanStation to measure submerged gravel beds. Figure 3 shows the point cloud before and after the correction. One brick (Small: $10 \mathrm{~cm}$ x $10 \mathrm{~cm}$ x $6 \mathrm{~cm}$ ) and cement block (Large: $10 \mathrm{~cm}$ x $20 \mathrm{~cm}$ x $6 \mathrm{~cm}$ ), which were colour taped at different surfaces for better recognition of the edges, were sunken in each plot.
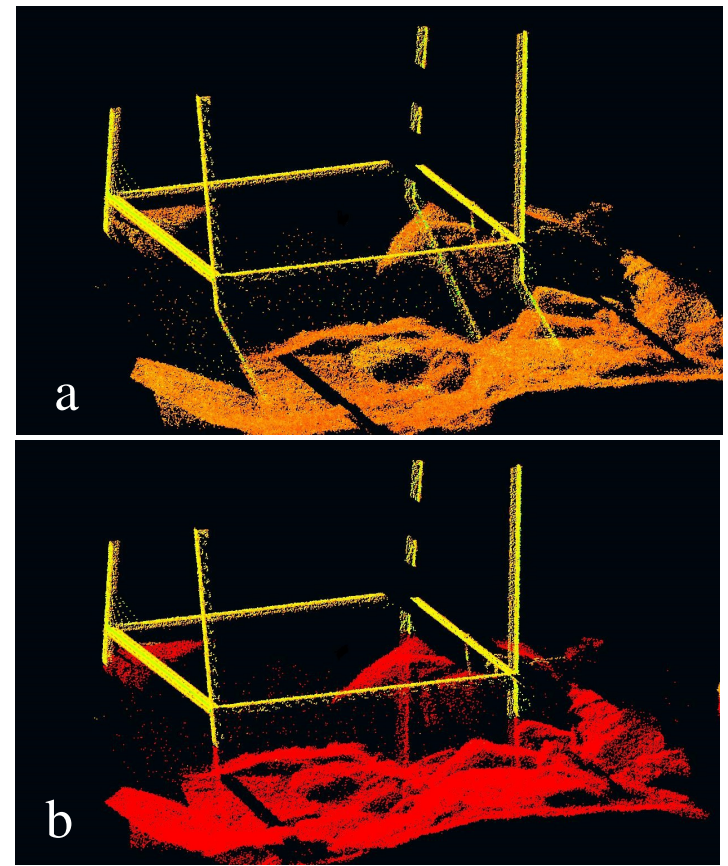

Figure 3. Point cloud before (a) and after (b) the water refraction correction. Uncorrected underwater data (submerged frame posts and stream-bed point cloud) appear to be higher than the actual position and away from the scanner origin. 


\subsection{Field data}

Field data was collected within a TLS survey of the mountain channel. Four rectangle plots $(1.14 \mathrm{~m}$ x $1.14 \mathrm{~m})$ were set up and levelled in the channel, placing two plots (Plot 2 and Plot 3) in shallow area and the other two (Plot 1 and Plot 4) in deeper area of the channel (Figure 4). Perpendicular lines were fixed to create 16 grids $(0.285 \mathrm{~m} \times 0.285 \mathrm{~m})$ within a plot. The flow velocity was measured at $60 \%$ of the water depth from the water surface using Electro Magnetic Velocity Meter VP1000 (KENEK CO., LTD.). It was recorded at four corners of the grids, resulting in 25 recordings in a plot. The location of these 25 observation points in each plot was recorded using Total Station with prism and detail pole, which consequently provides survey based water depth at each observation point. The water depth to sunken objects was also recorded.

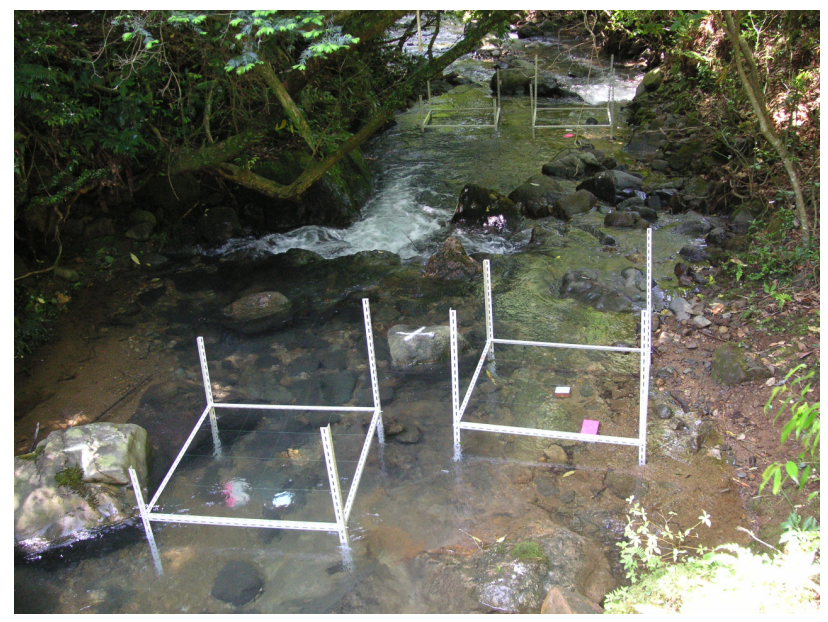

Figure 4. Plots in the mountain channel

\subsection{Validation}

In order to validate TLS data, DTM of the channel bed was created for each plot (Figure 5), using the water refraction corrected data of TLS survey. Single measurement data was used for each plot. Data processing was conducted using Leica's software, Cyclone. The grid size was $0.5 \mathrm{~cm} \times 0.5 \mathrm{~cm}$. Then, water depth was calculated at 25 observation points, using the DTM and the water level which was identified in the point cloud. The accuracy of water depth should be a good indication how well stream-bed was acquired by TLS. These TLS based water depth was compared with survey based water depth. Using a Generalized Liner Model (GLM), the water depth and flow velocity were statistically examined whether they have any effect on acquiring the stream-bed data by TLS. The statistical analysis was performed with software $\mathrm{R}$ version 2.15.0 (R Development Core Team, 2012). The sunken objects were identified in the point cloud and their surfaces were extracted using the model function of Cyclone.

\section{RESULTS}

TLS measurement for 4 plots was summarized in Table 1. All data were collected within $5 \mathrm{~m}$ from the scanner location. Number of returns from each plot varied, ranging from 132071 (Plot 1) to 458876 (Plot 2). Data for observation points No.2225 in Plot 4 were found to be absent since some parts of the Plot 4 fell into too close range from the sensor (Figure 6).
Table 1. Summary of TLS data acquisition

\begin{tabular}{|c|c|c|c|c|}
\hline \multirow[t]{2}{*}{ Plot } & \multicolumn{2}{|c|}{$\begin{array}{c}\text { Distance of } \\
\text { measurement }(\mathrm{cm})\end{array}$} & \multirow{2}{*}{$\begin{array}{c}\text { Scanner height } \\
(\mathrm{cm})\end{array}$} & \multirow{2}{*}{$\begin{array}{l}\text { Number } \\
\text { of returns }\end{array}$} \\
\hline & Max. & Min & & \\
\hline 1 & 468.2 & 351.3 & 199.0 & 132071 \\
\hline 2 & 322.3 & 185.2 & 200.3 & 458876 \\
\hline 3 & 393.3 & 232.8 & 127.5 & 380720 \\
\hline 4 & 251.2 & 120.7 & 127.8 & 392162 \\
\hline
\end{tabular}

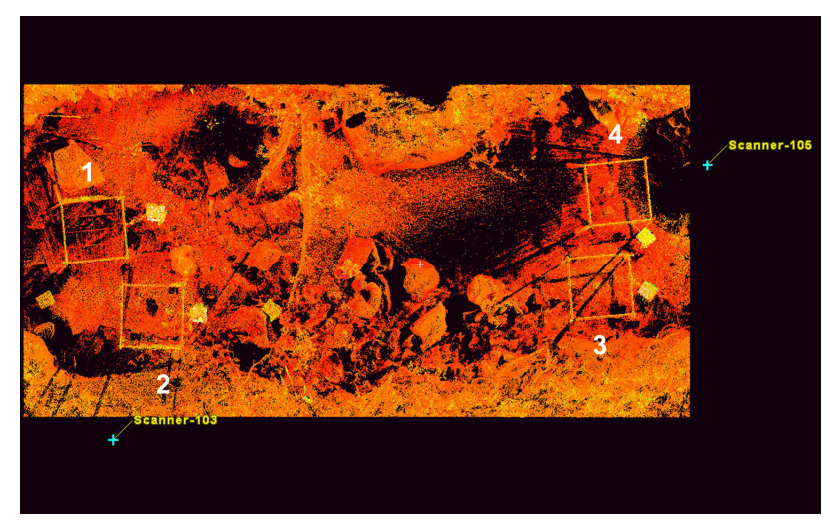

Figure 6. TLS measurement over study area. Numbers correspond to the plot names.

\subsection{Comparison of water depth}

The water depth obtained by survey ranged from $3.6 \mathrm{~cm}$ to 62.3 $\mathrm{cm}$ in the 4 plots. The comparison between TLS based and survey based water depth was shown in Figure 7. The water depth derived by these two methods was positively correlated, presenting r-squire value of 0.51 for Plot 1, 0.94 for Plot 2, 0.66 for Plot 3 and 0.73 for Plot 4. Root Mean Square Error (RMSE) of TLS based water depth against survey based water depth was 6.25 for Plot 1, 2.63 for Plot 2, 3.11 for Plot 3 and 3.03 for Plot 4.

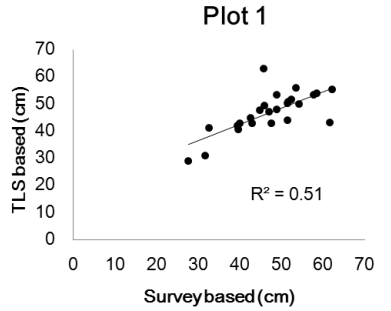

Plot 3

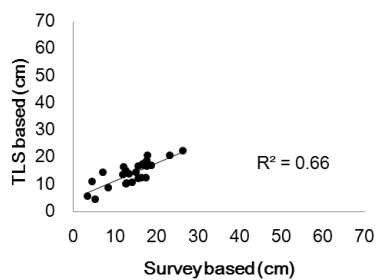

Figure 7. Comparison of water depth derived by TLS and

survey

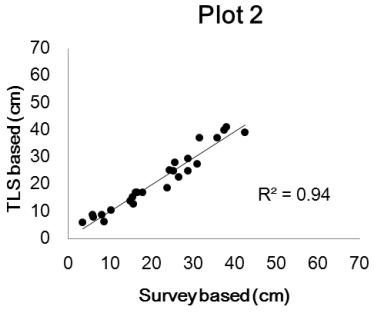

Plot 4

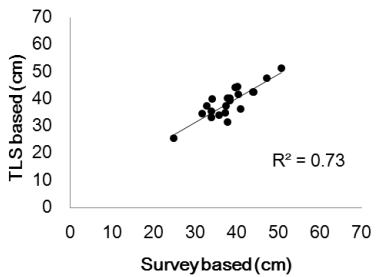


ISPRS Annals of the Photogrammetry, Remote Sensing and Spatial Information Sciences, Volume II-5/W2, 2013 ISPRS Workshop Laser Scanning 2013, 11 - 13 November 2013, Antalya, Turkey
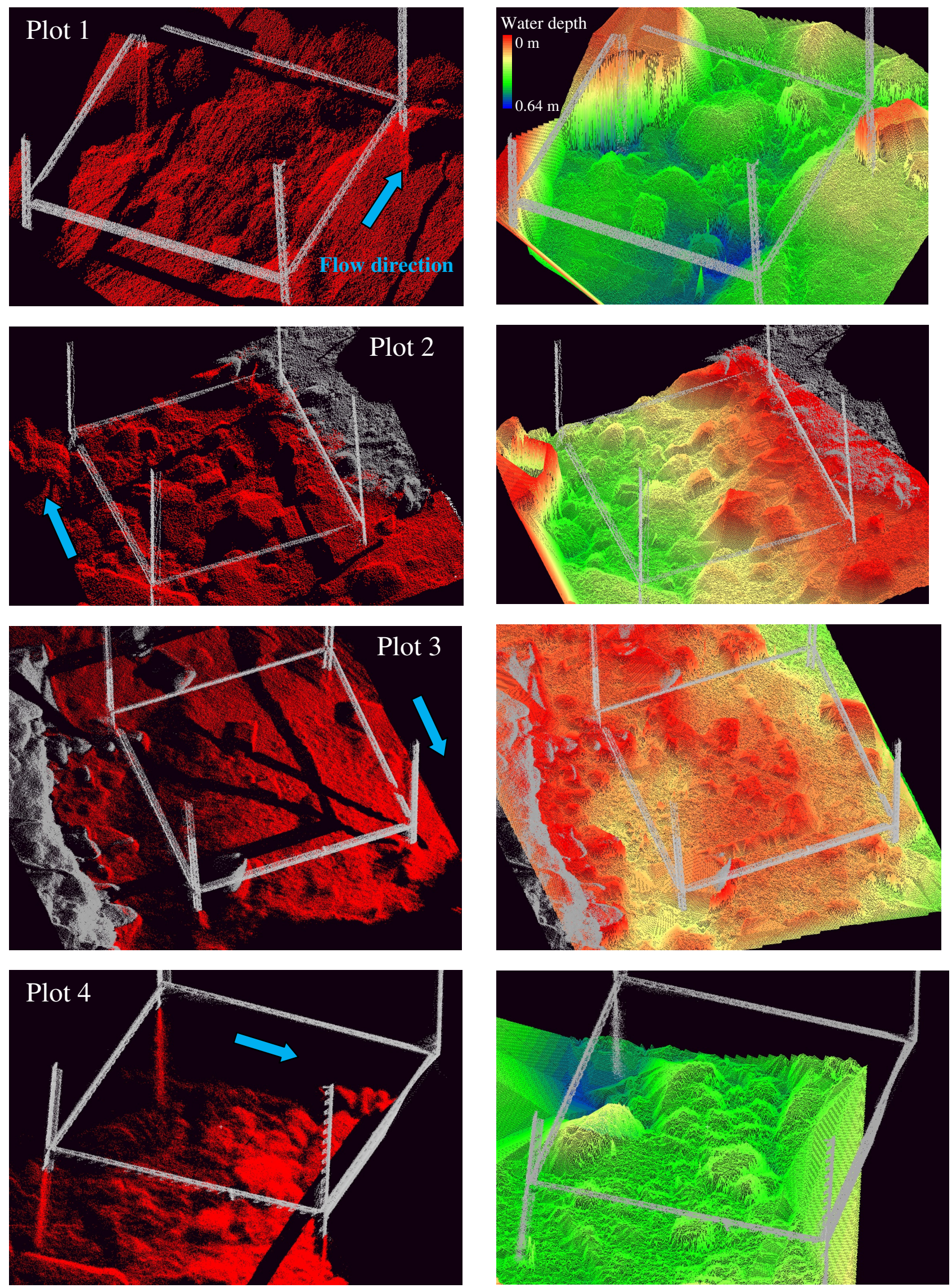

Figure 5. Water refraction corrected point cloud (left) and DTM (right) for the 4 plots 


\subsection{Effect of water depth and flow velocity}

3.2.1 Flow velocity: Figure 8 displays a box plot of the flow velocity recorded at 25 observation points in each plot. The recorded flow velocity includes negative values, which means water flows opposite direction against the current. Therefore, they were converted to absolute values to compare their rate. The flow velocity was highest in Plot 1 and lowest in Plot 2, however, varied within a plot. The pairwise comparison using $t$ tests, in which $\mathrm{p}$ value was adjusted by bonferroni method, indicated that Plot 1 is similar to Plot 3 and 4 in terms of variation of flow velocity in each plot. Plot 2 and 3 were somewhat similar if not significant.

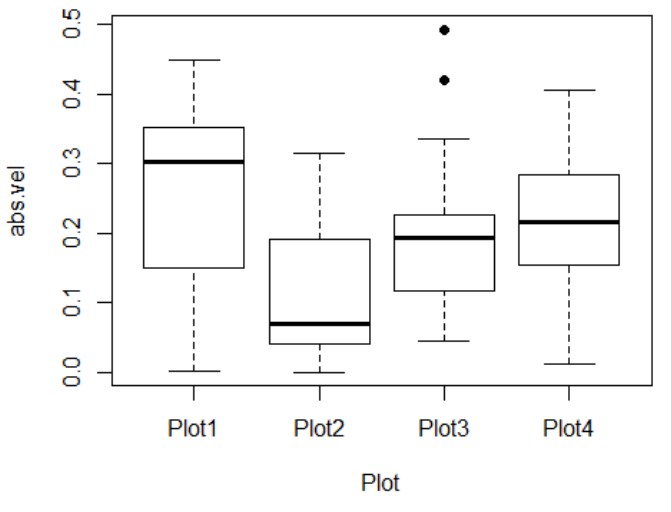

Figure 8. Flow velocity (absolute values) in each plot.

3.2.2 GLM analysis: In order to examine the effect of water depth, flow velocity and their interaction on the accuracy of TLS measurement, a GLM was developed (Table 2). Dependent variable is the difference between TLS and survey based water depth. Independent variables are plot, survey based water depth, flow velocity, and the interaction between survey based water depth and flow velocity. The analysis excluded the effect of plot, the water depth and flow velocity. However, it indicated some effect of the interaction between survey based water depth and flow velocity.

Table 2. Variables in GLM for the effect of water depth, flow velocity and their interaction on the accuracy of TLS measurement

\begin{tabular}{lccc} 
& Estimate & Std.Error & $\mathrm{t}$ value \\
\hline (Intercept) & 0.51914 & 1.83182 & 0.283 \\
Plot1 vs Plot2 & 0.68634 & 1.25441 & 0.547 \\
Plot1 vs Plot3 & 1.99857 & 1.52400 & 1.311 \\
Plot1 vs Plot4 & -0.39619 & 0.93097 & -0.426 \\
Flow velocity & -7.75294 & 6.17835 & -1.255 \\
Survey water depth & 0.02992 & 0.03945 & 0.759 \\
Survey water depth x & 0.35680 & 0.17587 & $2.029 *$ \\
flow velocity & & & \\
AIC: 476.05 & & & \\
*P $<0.05$. & & &
\end{tabular}

\subsection{Extraction of submerged objects}

Table 3 exhibits the results of automated extraction of submerged objects. Small object in Plot 1, and Large and Small objects in Plot 3 were visually recognizable in the point cloud, however, the surfaces of these objects could not be automatically extracted. The error of extraction was found to be maximum $+3.4 \mathrm{~cm}$ in Plot 4 and minimum $+0.1 \mathrm{~cm}$ in Plot 2 . The comparison between actual and TLS based water depth at which the objects were placed resulted in RMSE of 0.75 for all records.

Table 3. The results of automated extraction of submerged objects

\begin{tabular}{|c|c|c|c|c|c|c|}
\hline \multirow[b]{2}{*}{ Plot } & \multirow[b]{2}{*}{ Object } & \multirow[b]{2}{*}{ Dimension } & \multicolumn{2}{|c|}{ Size $(\mathrm{cm})$} & \multicolumn{2}{|c|}{ W. depth (cm) } \\
\hline & & & Actual & TLS & Actual & TLS \\
\hline \multirow[t]{4}{*}{1} & \multirow[t]{2}{*}{ Large } & Depth & 10 & 11.8 & \multirow[t]{2}{*}{42.5} & \multirow[t]{2}{*}{42.4} \\
\hline & & Width & 20 & 21.4 & & \\
\hline & \multirow[t]{2}{*}{ Small } & Depth & 10 & N/A & \multirow[t]{2}{*}{51.5} & \multirow[t]{2}{*}{50} \\
\hline & & Width & 10 & N/A & & \\
\hline \multirow[t]{4}{*}{2} & \multirow[t]{2}{*}{ Large } & Depth & 10 & 10.3 & \multirow[t]{2}{*}{8.5} & \multirow[t]{2}{*}{8.9} \\
\hline & & Width & 20 & 20.1 & & \\
\hline & \multirow[t]{2}{*}{ Small } & Depth & 10 & 10.8 & \multirow[t]{2}{*}{16} & \multirow[t]{2}{*}{16.3} \\
\hline & & Width & 10 & 10.3 & & \\
\hline \multirow[t]{4}{*}{3} & \multirow[t]{2}{*}{ Large } & Depth & 10 & N/A & \multirow[t]{2}{*}{4} & \multirow[t]{2}{*}{3.6} \\
\hline & & Width & 20 & N/A & & \\
\hline & \multirow[t]{2}{*}{ Small } & Depth & 10 & N/A & \multirow[t]{2}{*}{3.5} & \multirow[t]{2}{*}{3.4} \\
\hline & & Width & 10 & N/A & & \\
\hline \multirow[t]{4}{*}{4} & \multirow[t]{2}{*}{ Large } & Depth & 10 & 12.5 & \multirow[t]{2}{*}{34.5} & \multirow[t]{2}{*}{33.6} \\
\hline & & Width & 20 & 23.3 & & \\
\hline & \multirow[t]{2}{*}{ Small } & Depth & 10 & 13.4 & \multirow[t]{2}{*}{34.5} & \multirow[t]{2}{*}{33.5} \\
\hline & & Width & 10 & 12.3 & & \\
\hline
\end{tabular}

\section{DISCUSSION}

The results of comparison of water depth derived by TLS and survey displayed significant correlation between them for Plot 2, 3 and 4 (Figure 7). The RMSE for these plots was less than 3.11 $\mathrm{cm}$. Considering that there could be always errors of survey measurement over complex, coarse gravel stream-bed, and the water surface was constantly disturbed by the wind and flow, this might be still within an acceptable accuracy for the measurement of water depth. Plot 1 showed lower r-square value of 0.51 and RMSE of $6.25 \mathrm{~cm}$. This was mainly caused by the two recordings at the observation point 7 and 8 . It was found that the DTM was interpolated with particularly fewer points around these observation points. This part of DTM may not represent the stream-bed correctly. With exclusion of these two recordings, overall $r$-square value and RMSE for Plot 1 were improved as 0.82 and $3.81 \mathrm{~cm}$, respectively. We used single measurement data by TLS for this analysis, which caused lack of returns in some area due to occlusion, i.e., obstacles in the path of pulsed laser such as a frame of the plot and submerged large rocks. Plot 1 was found to have fewer returns compared to other plots (Table 1). This is because the streambed in Plot 1 formed valley-like topology by large rocks, which would have caused lack of returns for the single measurement. This would be improved by combining data measured from multiple directions. As an overall trend, TLS based water depth in Plot 1 and 3 seems to be underestimated compared to the survey based one (Figure 7). This could be also resulted from inaccurate parts of DTM due to occlusion, rather than systematic error of TLS. Noise, i.e., non-surface points might be another reason to create inaccurate parts of DTM and consequently underestimate the water depth. Filtering to remove noise data may improve the accuracy of DTM as Hodge et al. (2009) described.

The GLM analysis showed that each of water depth and flow velocity alone does not affect the accuracy of TLS measurement in this research (Table 2). In fact, Plot 4, which was set up in deeper area of the channel, exhibits better r-square value and RMSE than Plot 3 which located in shallower area (Figure 7). These two plots have similar variation of flow velocity (Figure 
8). This fits the result of Smith et al. (2012) who tested the precision of TLS with increasing water and concluded that the through-water scanning method maintains the achievable precision up to $200 \mathrm{~mm}$ of clear water. The GLM analysis also indicates that the interaction between water depth and flow velocity may have an influence on the accuracy of TLS measurement (Table 2). Since Plot 2 which located in shallow area with low flow velocity displayed the best results with $\mathrm{r}$ square of 0.94 and RMSE of $2.63 \mathrm{~cm}$ among the 4 plots (Figure 7 ), this might be true. However, this needs further research to confirm.

In automated extraction of submerged objects, the surfaces of the two objects in Plot 2 were well extracted with maximum error of $+0.8 \mathrm{~cm}$ (Table 3). The rest of extracted objects placed deeper in the channel were also overestimated their dimension, however, with much lower accuracy (maximum error of +3.4 $\mathrm{cm})$. Since the water depth where the objects were placed was obtained relatively well with RMSE of $0.75 \mathrm{~cm}$ for all objects, the vertical error of measurement for these objects was considered not to be significant. The water depth might have some relation to the over-estimation of the depth and width of the objects, i.e., horizontal error. However, it could be resulted from the interaction between water depth and flow velocity as we discussed above. This assumption also requires further study to be clarified. The unsuccessful objects for automated extraction were found to have insufficient points. The small object in Plot 1 was placed at the bottom of "valley" in the stream-bed, which would have caused lack of returns from the object. A part of two objects in Plot 3 was found to be in the shadow of frames of the plot. This would be solved by increasing the returns from the objects by means of combining multiple data acquired from different direction.

\section{CONCLUSION}

In conclusion, the preliminary analysis which was conducted in a steep mountain channel with flow and complex stream-bed up to approximately $70 \mathrm{~cm}$ deep, showed good performance of green-wavelength TLS for measurement of submerged streambed. The ability of green-wavelength TLS for through-water measurement in the natural fluvial environment was promising. It was indicated that each of water depth and flow velocity alone does not affect the accuracy of TLS measurement, however, the interaction between water depth and flow velocity may have an influence. The attempt to automatically extract the dimension of submerged objects was partially successful. Combining multiple data acquired from different direction and filtering to remove noise data would improve the accuracy of TLS measurement to some extent. In order to identify the factors to affect the accuracy of TLS through-water measurement, further research is required.

\section{REFERENCES}

Asano, Y., Uchida, T., 2013. Dynamic changes in flow and channel resistance during floods at steep moutain stream, in: Advances in River Sediment Research-Fukuoka et al. (Ed.), 12th International Symposium on River Sedimentation ISRS2013. Taylor \& Francis Group, Kyoto, Japan, pp. 737-742.

Butler, J., Lane, S., Chandler, J., Porfiri, E., 2002. ThroughWater Close Range Digital Photogrammetry in Flume and Field Environments. The Photogrammetric Record 17, 419-439.

Hodge, R., Brasington, J., Richards, K., 2009. In situ characterization of grain-scale fluvial morphology using
Terrestrial Laser Scanning. Earth Surface Processes and Landforms 34, 954-968.

Large, A.R.G., Heritage, G.L., 2009. 1 Laser Scanning Evolution of the Discipline, in: Large, A.R.G., Heritage, G.L. (Eds.), Laser scanning for the environmental sciences. WileyBlackwell, Chichester.

Lee, A.J., Ferguson, R.I., 2002. Velocity and flow resistance in step-pool streams. Geomorphology 46, 59-71.

Leica Geosystems, 2013. Leica ScanStation C10.

Milan, D.J., Heritage, G.L., Large, A.R.G., Entwistle, N.S., 2010. Mapping hydraulic biotopes using terrestrial laser scan data of water surface properties. Earth Surface Processes and Landforms 35, 918-931.

Montogomery, D.R., Buffington, J.M., 1997. Channel-reach morphology in mountain drainage basins. Geol. Soc. Am. Bull. 109, 596-611.

R Development Core Team, 2012. R: a language and environment for statistical computing. $\mathrm{R}$ Foundation for Statistical Computing, Vienna.

Smith, M., Vericat, D., Gibbins, C., 2012. Through-water terrestrial laser scanning of gravel beds at the patch scale. Earth Surface Processes and Landforms 37, 411-421.

Wilcox, A.C., Nelson, J.M., Wohl, E.E., 2006. Flow resistance dynamics in step-pool channels: 2. Partitioning between grain, spill, and woody debris resistance. Water Resources Research 42, W05419.

Wohl, E., 2010. Mountain rivers revisited, Water Resources Monograph 19. American Geophysical Union, Washington, DC.

Wohl, E., Cooper, D., Poff, L., Rahel, F., Staley, D., Winters, D., 2007. Assessment of Stream Ecosystem Function and Sensitivity in the Bighorn National Forest, Wyoming. Environmental Management 40, 284-302.

Zimmermann, A., Church, M., 2001. Channel morphology, gradient profiles and bed stresses during flood in a step-pool channel. Geomorphology 40, 311-327.

\section{ACKNOLEDGEMENTS}

The authors thank Mr. Toshinori Murayama (Leica Geosystems, K.K.) and Ms Naoko Fujiwara (the University of Tokyo) for their support and assistance. We also acknowledge Dr. Mark Smith (University of Leeds) for his valuable advice on the method of water refraction correction. This research was partially supported by Fund of the Japanese Ministry of Education and Culture for Science Research (23380081). 